\title{
EL IMPACTO DEL CASO ARTAVIA MURILLO EN MATERIA DE DERECHOS REPRODUCTIVOS
}

\section{THE IMPACT OF THE ARTAVIA MURILLO CASE ON REPRODUCTIVE RIGHTS}

\section{Andrés Oscar De Cicco'}

DOI: https://doi.org/10.37767/2591-3476(2020)24

\author{
Comentario a \\ Artavia Murillo y otros ("fecundación in vitro") y Caso Gómez Murillo y otros vs. \\ Costa Rica - Supervisión de cumplimiento de sentencias \\ Resolución de 22 de noviembre de 2019 \\ Corte Interamericana de Derechos Humanos
}

Disponible en

https://bit.ly/3aFJUpb

\section{RESUMEN:}

Las técnicas de reproducción asistida han contribuido a que personas biológicamente imposibilitadas para concebir puedan acceder a servicios de atención médica relacionados a la salud reproductiva en igualdad de condiciones que el resto de los individuos y, de ese modo, ver cumplimentado no solo su derecho humano de acceso a la salud, sino un conjunto de derechos fundamentales análogos como es el derecho a la vida privada y familiar y el derecho a formar una familia. En esta dirección, procederé a analizar la sentencia "Artavia Murillo vs. Costa Rica" dictada por la Corte Interamericana de Derechos Humanos. Si bien la sentencia recae sobre un caso en concreto, significó en la región un antes y un después en materia de derechos humanos y derechos reproductivos en particular, ya que recae sobre un tema en el que, aún en la actualidad, no existe un consenso político ni moral.

\begin{abstract}
Assisted reproduction techniques have contributed to the fact that people who are biologically unable to conceive can access to health care services related to reproductive health on equal terms with the rest of the individuals and, consequently, not only have their human rights to access to health fulfilled, but a set of similar fundamental rights such as the right to private and family life and the right to found a family. In this direction, I will proceed to analyze the judgment "Artavia Murillo vs. Costa Rica" issued by the Inter-American Court of Human Rights. Although the sentence falls on a specific case, it meant a before-and-after in the region in terms of human rights and reproductive rights in particular, since it falls on an issue on which even today there is no political or moral consensus.
\end{abstract}

1 Abogado (Universidad Nacional de Córdoba, Argentina); Escribano (Universidad Empresarial Siglo 21, Argentina); Máster en Gobernanza y Derechos Humanos (Universidad Autónoma de Madrid, España); Correo electrónico: deciccoandres@gmail.com. Nro. de ORCID: https://orcid.org/0000-0001-7833-6266. 
PALABRAS CLAVE: derechos reproductivos, fecundación in vitro, derecho a la vida, derecho formar una familia.

KEY WORDS: reproductive rights, in vitro fertilization, right to life, right to found a family.

\section{Introducción}

Toda persona tiene derecho a reproducirse. Configura una expresión básica de nuestro derecho fundamental a la libertad, a tomar nuestras propias decisiones y como queremos formar nuestro grupo familiar; nadie puede limitarnos ese derecho, ni siquiera el propio poder público. El derecho a reproducirse además de verse reflejado con nuestro derecho a ser libres, se vincula también con el derecho a la vida privada, a la intimidad personal y familiar, el derecho a fundar una familia y el derecho a acceder a los servicios de salud en todas sus formas.

Ahora bien, dicho esto, parecería que todos gozamos de la capacidad natural de poder procrear, sin embargo, la capacidad reproductiva es una condición que no todos los hombres y mujeres poseen. Clínicamente la infertilidad es definida por la Organización Mundial de la Salud como una enfermedad del sistema reproductivo definida por la incapacidad de lograr un embarazo clínico después de 12 meses o más de relaciones sexuales no protegidas ${ }^{2}$. Está claro que desde la propia letra de la ley surge que las personas con problemas de fertilidad gozan de los mismos derechos reproductivos que las personas fértiles, lo que no queda claro es si las primeras pueden ejercer los mismos derechos que las segundas.

En el presente informe se llevará un cabo un análisis de lo ocurrido en Costa Rica, cuando el Máximo Tribunal de dicho país decide prohibir la práctica de Fecundación In Vitro por atentar contra el derecho a la vida de los embriones. Esta decisión lleva a que por primera vez la Corta Interamericana de Derechos Humanos (en adelante, "la Corte" o "Tribunal de San José") se pronuncie sobre el asunto, significando un momento trascendental en la historia del Sistema Interamericano de Derechos Humanos, ya que se toma posición sobre uno de los temas jurídicos más debatidos tanto a nivel doctrinal, legislativo y jurisprudencial y que giran en torno al contenido de los derechos reproductivos. Si bien la sentencia a la que arriba la Corte es sobre el caso concreto, su significado y consecuencias se extenderán hacia todos los Estados del continente americano y repercutirá sobre otros temas de salud sexual y reproductiva de igual trascendencia como es el caso de la interrupción voluntaria del embarazo o aborto.

\section{Derechos reproductivos como derechos humanos}

A través de los años los derechos reproductivos han atravesado en el ordenamiento internacional un largo camino hasta lo que conocemos actualmente. En un principio, los debates en torno a salud sexual y reproductiva estaban circunscriptos solo a debates demográficos o de crecimiento poblacional. Posteriormente, estos derechos comienzan, progresivamente, a ser receptados indirectamente en los cuerpos normativos de diferentes instrumentos internacionales comenzando con la Declaración Universal de los

2 Organización Mundial de la Salud. (2009). Glosario de terminología en Técnicas de Reproducción Asistida (TRA). Versión revisada y preparada por el International Committee for Monitoring Assisted Reproductive Technology (ICMART) y la Organización Mundial de la Salud, OMS. 
Derechos Humanos (1948), en donde se consagran un cúmulo de derecho irrenunciables tales como el derecho a la libertad, seguridad, integridad física, libertad de expresión, entre otros; luego el Pacto Internacional de Derechos Civiles y Políticos y el Pacto Internacional de Derechos Económicos y Sociales (firmados en 1976); la Convención Internacional sobre la Eliminación de Todas las Formas de Discriminación Contra la Mujer (firmada en 1979); la Convención contra la Tortura y Otros Tratos o Penas Crueles, Inhumanos o Degradantes (firmada en 1984); la Convención sobre los Derechos del Niño (1990). En el ámbito interamericano, la Convención Americana sobre Derechos Humanos (1969) y el Protocolo Adicional de San Salvador también regulan sobre la materia.

Pero no fue hasta la Conferencia Internacional sobre Población y Desarrollo de Naciones Unidas (El Cairo, 1994) y la IV Conferencia Internacional de las Mujeres (Beijing, 1995) cuando se produce un cambio conceptual, donde se define de forma mas completa y acabada los términos "derechos reproductivos" y "salud reproductiva" como derechos humanos. En este sentido, el Informe de la Conferencia de El Cairo definía a la salud reproductiva como "un estado general de bienestar físico, mental y social, y no sólo de mera ausencia de enfermedades o dolencias [...]. Entraña la capacidad de disfrutar de una vida sexual satisfactoria y sin riesgos y de procrear, y la libertad para decidir hacerlo o no hacerlo, cuándo y con qué frecuencia. Esta última condición lleva implícito el derecho del hombre y la mujer a obtener información y de planificación de la familia de su elección, así como a otros métodos para la regulación de la fecundidad que no estén legalmente prohibidos, y acceso a métodos seguros, eficaces, asequibles y aceptables"3. Y agrega, "toda persona tiene derecho al disfrute del más alto nivel posible de salud física y mental. Los Estados deberían adoptar todas las medidas apropiadas para asegurar, en condiciones de igualdad entre hombres y mujeres, el acceso universal a los servicios de atención médica, incluidos los relacionados con la salud reproductiva, que incluye la planificación de la familia y la salud sexual. Los programas de atención de la salud reproductiva deberían proporcionar los más amplios servicios posibles sin ningún tipo de coacción. Todas las parejas y todas las personas tienen el derecho fundamental de decidir libre y responsablemente el número y el espaciamiento de sus hijos y de disponer de la información, la educación y los medios necesarios para poder hacerlo"4.

Por su parte, en la IV Conferencia Internacional de las Mujeres de Beijing de 1995 los Estados se comprometen a garantizar la igualdad de acceso y la igualdad de trato de hombres y mujeres en torno a la atención de la salud y a promover la salud sexual y reproductiva ${ }^{5}$. Asimismo, además de ratificar el concepto de salud reproductiva de la Conferencia de El Cairo, consagra el derecho de las mujeres el poder decidir libre de toda coerción y violencia cuestiones relativas a su salud sexual y reproductiva ${ }^{6}$.

Tanto respecto a la Conferencia de El Cairo como la de Beijing, pese a ser instrumentos no vinculantes o de soft law, existe un consenso dentro de la comunidad internacional de garantizar su inclusión, constituyendo hitos claves en materia de salud reproductiva, ya que conceptualizan y sientan las bases de lo que por ella se entiende, poniendo el foco de atención en el individuo y su capacidad de elección y en como ejercer el derecho a una salud sexual y reproductiva sin ningún tipo de coerción o limitaciones.

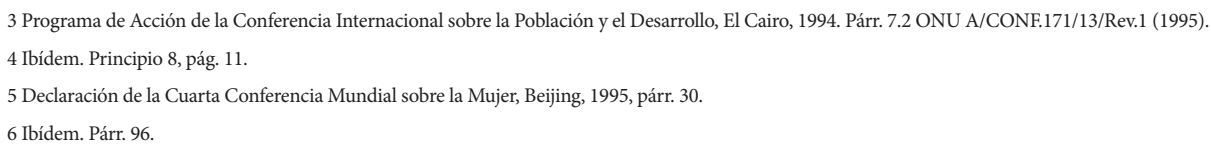


Esta visibilidad que logran en el ordenamiento internacional derechos que históricamente fueron considerados dentro de la faz privada, implica un importante paso hacia su regulación y consolidación como derechos humanos fundamentales. Además, significan grandes avances en cuanto a temas de género y derechos de las mujeres; no se puede hablar de derechos humanos de las mujeres sin hablar de derechos reproductivos, ya que estos son parte inescindible de aquellos.

\section{Técnicas de Reproducción Humana Asistida}

Aquellas personas y/o parejas que padezcan de infertilidad y no obstante decidan tener descendencia, deberán acudir a las llamadas Técnicas de Reproducción Humana Asistida (en adelante, TRHA). Este tipo de técnicas se abren paso como un modo alternativo de procreación en donde se pone en juego múltiples debates éticos y jurídicos y en donde entran en pugna los derechos humanos.

Las TRHA hacen referencia a un conjunto de diferentes tratamientos médicos que son utilizados con el fin de ayudar a personas y/o parejas infértiles a constituir un embarazo. La Organización Mundial de la Salud define a las TRHA como "todos los tratamientos o procedimientos que incluyen la manipulación tanto de ovocitos como de espermatozoides o embriones humanos para el establecimiento de un embarazo. Esto incluye, pero no está limitado sólo a, la fecundación in vitro y la transferencia de embriones, la transferencia intratubárica de gametos, la transferencia intratubárica de zigotos, la transferencia intratubárica de embriones, la criopreservación de ovocitos y embriones, la donación de ovocitos y embriones, y el útero surrogado. Ello no incluye inseminación asistida (inseminación artificial) usando espermatozoides ni de la pareja ni de un donante"7.

En cierto modo estos tipos de técnicas, como consecuencia de los avances científicos y tecnológicos, han venido a ocupar un rol clave dentro del campo de los derechos sexuales y reproductivos, satisfaciendo un conjunto de derechos fundamentales análogos que de otra manera sería impensado o dificultaría dicha satisfacción, tal como el derecho a la vida familiar o el derecho a formar una familia y a decidir la forma de su constitución. En muchos casos, resultan ser la única posibilidad que personas y/o parejas infértiles tienen para constituirse en padres, poder formar una familia y construir un proyecto de vida.

No obstante, las TRHA acarrean una serie de inconvenientes a resolver. Por un lado, hay una marcada reticencia de muchos estados en garantizar su reglamentación ya que su práctica incurriría en supuestas violaciones de otros derechos fundamentales reconocidos, principalmente el derecho a la vida. Por el otro, ponen al sistema jurídico universal en un apriete, desde el momento en que la ciencia interfiere en la naturaleza y los avances científicos y tecnológicos impactan en la vida de las personas. Estos avances precisan de ordenamientos jurídicos que se encuentren a la altura, con leyes y políticas públicas que puedan exteriorizar estos cambios y producir un impacto positivo en la sociedad.

En el siguiente apartado procederé a analizar como la Corte, bajo el ejercicio de sus competencias contenciosas, delimita los derechos que están en juego, estableciendo una ponderación de los mismos y se inclina por proteger a las personas que, valiéndose de su libertad de autodeterminación y su derecho a formar una familia, deciden someterse a procedimientos de fertilización in vitro.

7 Organización Mundial de la Salud. (2010). Glosario de terminología en Técnicas de Reproducción Asistida (TRA). Versión revisada y preparada por el International Committee for Monitoring Assisted Reproductive Technology (ICMART) y la Organización Mundial de la Salud, OMS. 


\section{El Caso Artavia Murillo y otros vs. Costa Rica. Hechos}

En Costa Rica, desde febrero del año 1995, mediante Decreto Ejecutivo emitido por el Ministerio de Salud, se autorizaba y reglamentaba la ejecución de la técnica de reproducción asistida de Fecundación In Vitro (en adelante, FIV) para todas aquellas parejas conyugales que así lo solicitasen. Dicha práctica fue efectuada en el país hasta marzo del año 2000 cuando la Sala Constitucional de la Corte Suprema de Justicia (en adelante, la Sala) declara la inconstitucionalidad del decreto argumentando, en primera media, infracción al principio de reserva legal al regular sobre derechos que deberían ser regulados mediante ley formal emanada del Poder Legislativo ${ }^{8}$. En segundo término, bajo el argumento que la práctica de la técnica FIV implica (por acción u omisión) una elevada pérdida de embriones, la Sala concluyó que llevar a cabo dicha práctica significaba un claro atentado contra el derecho fundamental a la vida reconocido en el art. 21 de la Constitución Política de Costa Rica y art. 4 de la Convención Americana sobre Derechos Humanos?

Iniciado el proceso ante el Sistema Interamericano de Derechos Humanos, la Comisión Interamericana de Derechos Humanos formula una serie de recomendaciones al Estado de Costa Rica a los fines de resolver el conflicto. Frente a la falta de acatamiento de dichas recomendaciones, el caso queda sometido a competencia de la Corte. Su misión es determinar si la decisión de la Sala (de prohibir la FIV) compromete la responsabilidad internacional del Estado de Costa Rica y, como consecuencia de ello, viola derechos humanos reconocidos en la Convención Americana sobre Derechos Humanos (en adelante, la Convención).

Finalmente, la Corte decide sobre el fondo de la cuestión condenando a Costa Rica como responsable internacional al haber vulnerado derechos fundamentales de los demandantes como el derecho a la vida privada y familiar y el derecho a la integridad personal en relación con la autonomía personal, el derecho a formar una familia y a decidir la forma de su constitución, el derecho a la salud sexual, el derecho a gozar de los beneficios del progreso científico y tecnológico, así como el principio de no discriminación ${ }^{10}$.

\section{Medidas Reparatorias}

La Corte, además de condenar como responsable internacional al Estado de Costa Rica por violación de derechos consagrados en la Convención, fija tres medidas reparatorias orientadas a constituirse en garantías de no repetición y en encausar la conducta del Estado en sus obligaciones internacionales. Primero, ordena que se tomen las medidas necesarias a los fines de dejar sin efecto la prohibición de practicar la FIV y cese en su actitud discriminatoria a los fines de que toda persona que lo solicite pueda tener acceso a dicha práctica. Segundo, la correspondiente regulación de la puesta en práctica de la técnica y el establecimiento de instituciones y profesionales idóneos para su ejecución. Finalmente, ordena al Estado a incluir la FIV de forma gradual en el programa de salud del Seguro Social ${ }^{11}$.

\section{Caso Gómez Murillo y otros vs. Costa Rica}

Posteriormente a la sentencia de Artavia Murillo, con fecha 29 de noviembre de 2016, la

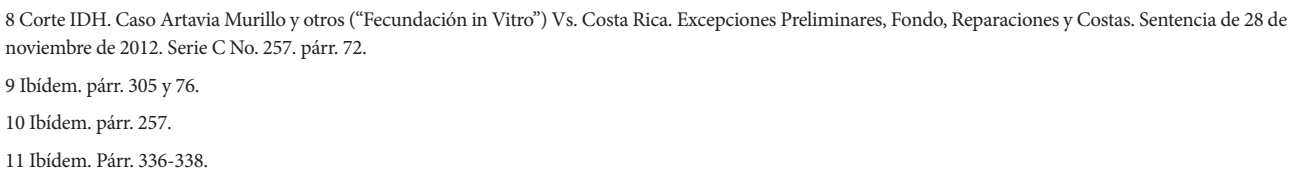


Corte decide sobre el caso Gómez Murillo y otros c. Costa Rica. Si bien ambos casos se fundan en el mismo hecho, el Tribunal de San José en este caso no va a decidir sobre el fondo del asunto, sino que procede a homologar un acuerdo de arreglo amistoso suscrito previamente entre las partes llamado "Acuerdo de arreglo amistoso suscrito entre el Estado de Costa Rica y la parte demandante". En dicho acuerdo, el Estado demandado reconoce su responsabilidad por la violación del derecho a la vida, a la integridad personal, a la libertad personal, a la protección de la honra y de la dignidad, a la protección de la familia y la igualdad ante la ley en perjuicio de los demandados ${ }^{12}$. La Corte consideró que el acuerdo producía plenos efectos jurídicos.

\section{Derechos reproductivos en función de otros derechos}

En primera medida, la Corte se propone a determinar el alcance del derecho a la vida privada y familiar y su vínculo con otros derechos fundamentales. Siguiendo el art. 11.2 de la Convención ${ }^{13}$, la Corte va mas allá y considera que la decisión de ser o no madre o padre forma parte del derecho a la vida privada independientemente de la forma utilizada para ello, sea la biológica o la genética ${ }^{14}$. Siguiendo este razonamiento, la Corte procede a utilizar criterios complementarios que vinculan el derecho a la vida privada con otros derechos consagrados tanto en la propia Convención, tal es el caso del derecho a fundar una familia (art. 17. $2^{15}$ ) o el derecho a la integridad personal (art. $5.1^{16}$ ) que se puede ver vulnerada ante la falta de accesibilidad a ciertas prestaciones de salud, como en fuentes análogas como la Convención para la Eliminación de todas las Formas de Discriminación contra la Mujer que consagra el derecho a la autonomía reproductiva (art. 16.[e]) ${ }^{17}$ y el derecho a acceder a los servicios de salud reproductiva, involucrando el derecho acceder a la tecnología médica necesaria para ejercer ese derecho. Estos derechos son vulnerados cuando se obstaculizan los medios para que una mujer pueda ejercer su derecho a controlar su fecundidad. ${ }^{18}$

En un punto cabe reconocer la tarea que realiza la Corte al establecer esta suerte de conexión entre los derechos reproductivos con el derecho a la vida privada, el derecho a fundar una familia, el derecho a la integridad personal, o el derecho a la salud. Sin embargo, esto revela la falta y, en consecuencia, la necesidad de un instrumento internacional vinculante en materia de derechos sexuales y reproductivos. El hecho que los derechos reproductivos sean definidos en función de otros derechos, revela su falta de autonomía y, por añadidura, dificulta la posibilidad de garantizarlos.

\section{Efectos de la prohibición de la FIV. Debate sobre los términos "concepción" y "persona"}

Otro punto importante que la Corte procede a analizar son los efectos que la prohibición de practicar la FIV podría acarrear. El Estado costarricense sostuvo que la prohibición de practicar este tipo de TRHA no era absoluta, en el sentido en que la FIV se podía practicar

\footnotetext{
12 Corte IDH. Caso Gómez Murillo y otros Vs. Costa Rica. Sentencia de 29 de noviembre de 2016. Serie C No. 326.

13 "Nadie puede ser objeto de injerencias arbitrarias o abusivas en su vida privada, en la de su familia, en su domicilio o en su correspondencia, ni de ataques ilegales a su honra o reputación".

14 Corte IDH. Caso Artavia Murillo y otros. Párr. 143

15 "Se reconoce el derecho del hombre y la mujer a contraer matrimonio y a fundar una familia si tienen la edad y las condiciones requeridas para ello por las leyes internas, en la medida en que éstas no afecten al principio de no discriminación establecido en esta Convención".

16 "Toda persona tiene derecho a que se respete su integridad física, psíquica y moral".

17 "[...]Los mismos derechos a decidir libre y responsablemente el número de sus hijos y el intervalo entre los nacimientos y a tener acceso a la información, la educación y los medios que les permitan ejercer estos derechos[...].

18 Corte IDH. Caso Artavia Murillo y otros. Párr. 145-147.
} 
siempre y cuando no implique pérdida de embriones. Contrariamente, la Corte constató que desde el momento en que la FIV fue prohibida no se llevó a cabo ninguna práctica de ese tipo en el país. Además, sostuvo que aún no hay posibilidad de garantizar fehacientemente que la FIV se practique sin que exista la posibilidad de pérdida embrionaria, tornando entonces de imposible cumplimiento la sentencia de la Sala y vulnerando el derecho a la vida privada y familiar de las parejas infértiles.

Seguidamente el razonamiento de la Corte, en su calidad de última intérprete de la Convención, procede a analizar el art. $4.1^{19}$ y sus alcances. Resulta interesante desatacar en este punto los diferentes criterios interpretativos que usa la Corte de San José para llegar a una decisión fundada. Se vale de un criterio sistemático, es decir, fundamenta su decisión no sólo acudiendo a otras disciplinas como es el caso de la biología y la medicina, sino teniendo en cuenta los diferentes sistemas internacionales de derechos humanos (interamericano, europeo, asiático, africano); apela al criterio evolutivo, que considera a los tratados de derechos humanos como instrumentos vivos, cuya interpretación tiene que acompañar la evolución de los tiempos actuales; y por último, tiene en cuenta el criterio teleológico fundando en el principio de interpretación más favorable y el objeto y fin del tratado.

Resaltando los puntos mas importantes, la Corte procede a determinar desde cuando comienza la vida humana y, por añadidura, desde cuando se puede establecer la existencia de un marco jurídico regulatorio que proteja al ser humano. Frente a la postura adoptada por el Estado de Costa Rica de protección absoluta del derecho a la vida desde el momento de la concepción, lo que es lo mismo, desde el momento en que se produce la fecundación o fertilización (en este caso), la Corte es contundente al afirmar que la concepción no se produce con la fecundación propiamente dicha sino se produce a partir de la implantación estable del embrión en el útero materno, condición sine que non para el desarrollo del embrión; antes de ese momento, el embrión no es considerado persona y no procede aplicar el art. 4.1 de la Convención ${ }^{20}$. La Corte concluyó que de las palabras "en general" contenidas en el art 4.1, no se deriva la protección absoluta del derecho a la vida sino mas bien un criterio de protección gradual y progresivo del derecho a la vida según su desarrollo, debido a que no constituye un deber absoluto e incondicional, sino que implica entender la procedencia de excepciones a la regla general ${ }^{21}$. Esta gradualidad o progresividad en la protección del derecho a la vida es, en definitiva, la que faculta la posibilidad de una protección de los derechos sexuales y reproductivos.

No debo dejar de mencionar que las tesis que toma la Corte en cuanto al término concepción y al término persona, según el cual el embrión no pueda ser considerado como tal en los términos de la Convención, significa un gran impacto dentro la comunidad internacional ya que allana el camino hacia un posible reconocimiento de la validez jurídica de la llamada píldora del día después, como así también, pese a que la Corte se avoque a decidir en el caso concreto sobre la validez de la prohibición de la técnica de fertilización in vitro, implica un importante paso hacia la despenalización del aborto en la región, fortaleciendo el derecho de las mujeres a disponer de su propio cuerpo.

\footnotetext{
19 "Toda persona tiene derecho a que se respete su vida. Este derecho estará protegido por la ley y, en general, a partir del momento de la concepción. Nadie puede ser privado de la vida arbitrariamente".

20 Corte IDH. Caso Artavia Murillo y otros. Párr. 186, 189.

21 Ibídem. Párr.264.
} 


\section{Voto en disidencia}

Resulta importante destacar, a efectos del análisis del fallo en cuestión, el voto disidente de uno de los miembros de la Corte. El argumento del Juez se centra en la interpretación del art. 4.1 de la Convención y fundamenta su postura en base al art. 31 de la Convención de Viena sobre el Derecho de los Tratados que fija reglas generales de interpretación de los tratados. En este sentido, el Magistrado sostiene que la misión principal de la Corte al momento de fallar es precisar la voluntad de los Estados al momento de suscribirse la Convención, de modo que les sea exigible aquello a lo que voluntariamente se comprometieron en su momento. Dicho esto, el Juez afirma que la expresión "persona", en los términos del art. 4.1, hace referencia a toda persona o ser humano sin distinción alguna. Por otra parte, la expresión "y en general, a partir de la concepción" no aludiría a una excepción o exclusión como sostiene la Corte, sino que es inclusiva: "hace aplicable la obligación de proteger por ley el derecho de toda persona a que se respete su vida desde la concepción"22. El propio Juez, realiza una interpretación literal del alcance del término "concepción", el cual significa fecundación.

\section{Juicio de Proporcionalidad. La tesis de discriminación indirecta}

Finalmente, la Corte procede a realizar un análisis de proporcionalidad de la prohibición de la FIV. En este sentido, la Corte siguió el criterio de la Organización Mundial de la Salud que definió la infertilidad como una enfermedad del sistema reproductivo, por lo tanto, las personas afectadas por la prohibición de practicar la FIV debieron haber sido destinatarias de los derechos de personas con discapacidad. La Corte de San José sostiene que no basta con que los Estados se abstengan de violar los derechos humanos, sino que estos deben llevar a cabo todas las acciones positivas que sean necesarias para asegurar su disfrute. En el caso analizado, el Estado de Costa Rica debe llevar a cabo todas las acciones necesarias que permitan la inclusión de personas con discapacidad, tendientes a asegurar la igualdad de condiciones, oportunidades y participación conjuntamente con los demás miembros de la sociedad. El Estado claramente vulneró el derecho de las parejas demandantes al interrumpir el tratamiento e impedir que tengan acceso a las técnicas de fertilización asistida accesibles en ese momento, a los fines de que pudieran superar esa situación natural de desventaja producto de su discapacidad.

Resulta interesante el aporte de la Corte cuando afirma que esta interferencia configura un claro ejemplo de discriminación indirecta ${ }^{23}$, ya que significa un impacto desproporcionado no solo para con las personas con discapacidad, sino para con las mujeres (ya que son las principales afectadas por la prohibición) y para aquellas personas con menos recursos económicos (ya que los ubica en una situación de desventaja respecto a aquellos que pueden afrontar el tratamiento en otro país). Por un lado, este aporte con perspectiva de género que hace la Corte, me parece sumamente necesario, ya que de una manera hace un reconocimiento de los reclamos de diversos grupos y organismos de defensa del derecho de las mujeres que vienen luchando durante años por la igualdad de derechos, y en este caso, en atención a las necesidades específicas de las mujeres cuando se trata de derechos reproductivos. Por el otro, el factor económico mencionado resulta interesante en el sentido de que aquellas personas con mayores recursos pueden eludir las trabas y/o limitaciones de acceso a la salud reproductiva en sus países y buscar una solución cruzando las fronteras nacionales. En cambio, la única opción que

22 Voto disidente del Juez Eduardo Vio Grossi. Corte IDH. Caso Artavia Murillo y Otros (“Fecundación In Vitro") Vs. Costa Rica Sentencia. 28 de noviembre de 2012 (Excepciones Preliminares, Fondo, Reparaciones Y Costas).

23 Corte IDH. Caso Artavia Murillo y otros. Párr. 284 y ss. 
tienen aquellas parejas y mujeres en situación económica mas desventajosa es acudir a métodos clandestinos, poniendo en peligro su propia salud e incluso su vida.

Seguidamente, el Tribunal de San José no consideró que el decreto declarado inconstitucional por la Sala sea desproporcionado, ya que en su articulado contemplaba medidas de protección para el embrión (limitando la cantidad de óvulos que podían ser fecundados). Lo que la Corte si encuentra desproporcionado es "pretender una protección absoluta del embrión respecto a un riesgo que resulta común e inherente incluso en procesos donde no interviene la técnica de la FIV"24, como sería el caso de un embarazo natural.

En síntesis, queda claro que el verdadero fondo del asunto ya no recae en determinar si hay o no un derecho a tener hijos o a formar una familia o a acceder a técnicas médicas de reproducción. Lo que pretende la Corte es echar luz sobre la interferencia desproporcionada por parte de un Estado y el impacto que ello ocasiona sobre derechos que son personalísimos y que pertenecen a la persona por su sola condición de ser humano.

\section{El Margen de Apreciación Nacional}

La falta de consensos entre los Estados sobre temas sensibles de derechos humanos, como podrían ser temas de interrupción voluntaria del embarazo, matrimonio igualitario o, como en este caso, la aplicación de técnicas de reproducción asistida, ha llevado a que los máximos tribunales regionales de derechos humanos, en este caso la Corte Interamericana de Derechos Humanos y Tribunal Europeo de Derechos Humanos (TEDH) decidan recurrir a la doctrina de margen de apreciación nacional ante la imposibilidad de aunar un criterio de interpretación y aplicación de algunos derechos. En este sentido, según afirma BARBOZA DELGADO "el margen nacional de apreciación debe ser comprendido como un reducto o "criterio" de interpretación y aplicación de los derechos humanos, atribuido al Estado por parte de los tribunales regionales"25.

Debe reconocerse que el margen nacional de apreciación es mas bien de aplicación europea. En este sentido el TEDH se ha expedido en diferentes casos acudiendo a esta doctrina, incluso en asuntos donde se ha discutido la protección de la persona por nacer ${ }^{26}$. En cambio, en el sistema interamericano la Corte ha sido reticente a utilizar esta figura. Si bien hay decisorios en que la Corte se ha valido de la doctrina de margen de apreciación para fundar sus argumentos ${ }^{27}$, no se puede decir que técnicamente haya usado esta figura para decidir sobre un conflicto.

En el caso objeto de estudio, resulta importante mencionar que uno de los argumentos utilizados por el Estado de Costa Rica en sus alegatos para justificar la prohibición de la FIV fue la invocación explícita del margen nacional de apreciación, alegando que no existe en la región un consenso en relación al estatus jurídico del embrión, ni sobre el inicio de la vida humana y que, por lo tanto, la decisión debía ser dejada en manos del legislador. Además, sostiene que no es válido el argumento de que "como existen otros Estados que, por omisión legislativa, permiten la practica de la FIV, Costa Rica ha perdido

\footnotetext{
24 Ibídem. Párr.311.

25 BARBOSA DELGADO, Francisco R. "El margen nacional de apreciación en el Derecho Internacional de los Derechos Humanos: entre el Estado de Derecho y la sociedad democrática". México: Universidad Nacional Autónoma de México. Instituto de Investigaciones Jurídicas, 2012, pp. 53.

26 Sentencia del TEDH, Vo vs. Francia, App. N 53924/00, julio 8, 2004. Sentencia del TEDH, Evans vs. Reino Unido, App. N 6339/05, abril 10, 2007.

27 Corte IDH, Caso Chaparro Álvarez y Lapo c. Ecuador. Sentencia del 21 de noviembre de 2007, párr. 107. Corte IDH, Caso Castañeda Guzmán c. México. Sentencia del 6 de agosto de 2008, párr. 162. Corte IDH, Caso Herrera Ulloa c. Costa Rica. Sentencia del 2 de iulio de 2004, párr. 161
} 
su margen de apreciación"28. La Corte, lejos de someter el caso a la discrecionalidad del Estado, concluyó sin más que una protección absoluta y categórica del embrión (es decir, sin excepciones) es claramente desproporcionada, de manera que ponerse analizar el grado de discrecionalidad del Estado al momento de decretar la prohibición no tiene ningún sentido ${ }^{29}$. Es decir, en vez de aplicar el margen de discrecionalidad, la Corte prefiere emplear el criterio de proporcionalidad.

\section{A modo de conclusión}

Somos parte de una sociedad que está en constante evolución y crecimiento y ello nos demuestra que determinadas situaciones fácticas o concretas superan los ámbitos legales de regulación, especialmente cuando se tratan temas relacionados al derecho a la salud y mas precisamente a la salud reproductiva. Sin dudas, el progreso científico y tecnológico y su repercusión en el campo de los derechos reproductivos, plantean grandes desafíos tanto para el derecho internacional de los derechos humanos como para los tribunales regionales, pese a que la historia nos ha demostrado que en determinados casos los ordenamientos internos no han sabido estar a la altura de las circunstancias. Claro ejemplo de ello lo vemos con la criminalización del aborto, donde hasta la fecha son muy pocos los países de América Latina que permiten la interrupción del embarazo sin condiciones en las primeras semanas de gestación, teniendo en cuenta los plazos establecidos en sus legislaciones internas.

Considero trascendental la tarea que deben cumplir los sistemas nacionales e internacionales de protección de derechos humanos en pos del "rejuvenecimiento" de diversas normas y políticas anacrónicas, para así poder dar respuestas a las demandas sociales que crecen y mutan no solo como consecuencia de los avances científicos y tecnológicos, sino como resultado a los cambios que experimenta la propia sociedad.

No se puede negar que la tarea efectuada por la Corte Interamericana de Derechos Humanos en el caso objeto de estudio ha sido fundamental para la consolidación y protección de los derechos reproductivos en la región, en cuanto ha sabido realizar una interpretación y una lectura de las obligaciones de los Estados en cuanto a su deber no solo de abstenerse de vulnerar el ejercicio de tales derecho fundamentales, sino de llevar a cabo todas las acciones o medidas necesarias que garanticen la autonomía reproductiva, el disfrute de los avances científicos y el acceso a las diferentes técnicas de reproducción asistidas.

Sin duda queda aún un largo camino por recorrer, pero este tipo de sentencias significan nuevos cambios en la concepción del goce y disfrute de los derechos humanos y los Estados y sus legislaciones deberán actuar en consecuencia. 


\section{REFERENCIAS BIBLIOGRÁFICAS}

- BARBOSA DELGADO, Francisco R. (2012) "El margen nacional de apreciación en el Derecho Internacional de los Derechos Humanos: entre el Estado de Derecho y la sociedad democrática". México: Universidad Nacional Autónoma de México. Instituto de Investigaciones Jurídicas.

- ORGANIZACION MUNDIAL DE LA SALUD. (2010). "Glosario de terminología en Técnicas de Reproducción Asistida (TRA)". Versión revisada y preparada por el International Committee for Monitoring Assisted Reproductive Technology (ICMART) y la Organización Mundial de la Salud, OMS.

\section{Instrumentos no vinculantes}

- Declaración de la Cuarta Conferencia Mundial sobre la Mujer, Beijing, 1995.

- Programa de Acción de la Conferencia Internacional sobre la Población y el Desarrollo, El Cairo, 1994.

\section{Jurisprudencia}

- Corte IDH. Caso Artavia Murillo y otros ("Fecundación in Vitro") vs. Costa Rica. Excepciones Preliminares, Fondo, Reparaciones y Costas. Sentencia de 28 de noviembre de 2012. Serie C No. 257.

- Caso Castañeda Gutman Vs. México. Excepciones Preliminares, Fondo, Reparaciones y Costas. Sentencia de 6 de agosto de 2008. Serie C No. 184.

- Caso Chaparro Álvarez y Lapo Íñiguez Vs. Ecuador. Excepciones Preliminares, Fondo, Reparaciones y Costas. Sentencia de 21 de noviembre de 2007. Serie C No. 170.

- Corte IDH. Caso Gómez Murillo y otros Vs. Costa Rica. Sentencia de 29 de noviembre de 2016. Serie C No. 326.

- Caso Herrera Ulloa Vs. Costa Rica. Sentencia de Excepciones Preliminares, Fondo, Reparaciones y Costas. Sentencia de 2 julio de 2004. Serie C No. 107. 